\title{
Extracellular Synthesis of cADP-Ribose from Nicotinamide-Adenine Dinucleotide by Rat Cortical Astrocytes in Culture
}

\author{
Ludmila Pawlikowska, Susan E. Cottrell, Matthew B. Harms, Ya Li, and Paul A. Rosenberg \\ Department of Neurology and Program in Neuroscience, Children's Hospital and Harvard Medical School, Boston, \\ Massachusetts 02115
}

\begin{abstract}
cADPR is an endogenous calcium-mobilizing agent that in vertebrates is synthesized from nicotinamide-adenine dinucleotide (NAD) by bifunctional enzymes with ADP-ribosyl cyclase and cADPR hydrolase activity. ADP-ribosyl cyclase and cADPR hydrolase activity have been reported in the brain, but the cellular localization of these activities has not been determined previously. In the present study, selective culturing techniques were employed to localize ADP-ribosyl cyclase activity and cADPR hydrolase activity to astrocytes or neurons in cultures derived from rat embryonic cerebral cortex. ADP-ribosyl cyclase activity was determined by incubating cultures with $1 \mathrm{~mm}$ $\mathrm{NAD}$ in the extracellular medium for $60 \mathrm{~min}$ at $37^{\circ} \mathrm{C}$ and measuring formation of CADPR by bioassay and by HPLC. Astrocyte cultures and mixed cultures of astrocytes and neurons had
\end{abstract}

mean specific activities of $0.84 \pm 0.06$ and $0.9 \pm 0.18 \mathrm{nmol}$ cADPR produced/mg protein/hr, respectively. No detectable ADP-ribosyl cyclase activity was found in neuron-enriched/ astrocyte-poor cultures. cADPR hydrolase activity was detectable by incubating cultures with $300 \mu \mathrm{M}$ CADPR for $60 \mathrm{~min}$ at $37^{\circ} \mathrm{C}$ and assaying loss of cADPR or accumulation of ADPR. The demonstration of extracellular ADP-ribosyl cyclase and cADPR hydrolase activities associated with astrocytes may have important implications for the role of extracellular cADPR in signal transduction and in intercellular communication in the nervous system.

Key words: cADP-ribose; NAD; ADP-ribosyl cyclase; cADPR hydrolase; astrocytes; extracellular enzymes; signal transduction; calcium
cADP-ribose (cADPR), an endogenous metabolite of nicotinamide-adenine dinucleotide (NAD), is a novel calciummobilizing agent implicated in the modulation of the ryanodine receptor (Lee, 1994). It was first discovered in sea urchin egg homogenates (Clapper et al., 1987) in which it was found to be completely independent of and more potent than inositol-1,4,5triphosphate $\left(\mathrm{IP}_{3}\right)$ in mobilizing calcium from intracellular stores (Dargie et al., 1990). Subsequently, it was found in most vertebrate and invertebrate tissues, including rat brain (Walseth et al., 1991). Increasing pharmacological evidence has implicated cADPR in the calcium-induced calcium-release process (CICR) and in the modulation of the activity of the ryanodine receptor (Galione et al., 1991; Currie et al., 1992; Lee, 1993; Meszaros et al., 1993; Lee et al., 1994). cADPR has been shown to induce calcium release in permeabilized rat pituitary cells (Koshiyama et al., 1991), rat brain microsomes (White et al., 1993), heart sarcoplasmic reticulum vesicles (Meszaros et al., 1993), and rat pancreatic cell microsomes (Takasawa et al., 1993a), as well as in electrophysiological studies in intact rat dorsal root ganglion neurons (Currie et al., 1992) and in cultured bullfrog sympathetic neurons (Hua et al., 1994), in which cADPR appeared to mediate calcium oscillations produced by CICR through the ryanodine receptor. In sea urchin egg microsomes, the formation of cADPR from NAD and subsequent calcium release is enhanced by cGMP (Galione et al., 1993). Because the synthesis of cGMP can be controlled by an intercellular messenger such as nitric oxide

\footnotetext{
Received April 12, 1996; revised May 31, 1996; accepted June 13, 1996.

This work was supported by National Institutes of Health Grants NS 26830 and NS 31353, and a Mental Retardation Core Grant to Children's Hospital.

Correspondence should be addressed to Dr. Paul Rosenberg, Enders Research Building, Department of Neurology, Children's Hospital, 300 Longwood Avenue, Boston, MA 02115.

Copyright (C) 1996 Society for Neuroscience $0270-6474 / 96 / 165372-10 \$ 05.00 / 0$
}

(Bredt and Snyder, 1989), this finding raises the interesting possibility of cADPR involvement in intercellular and intracellular signaling in the nervous system.

The enzyme responsible for cyclization, ADP-ribosyl cyclase, first identified in sea urchin eggs (Rusinko and Lee, 1989), is widely distributed in vertebrate and invertebrate tissues (Lee and Aarhus, 1991, 1993). The enzyme is membrane bound in most cell types with the exception of Aplysia ovotestis, sea urchin eggs, and dog testes, in which a soluble form is expressed. Extensive amino acid sequence homology was found between the Aplysia ADPribosyl cyclase and the extracellular domain of the human lymphocyte antigen CD38 (States et al., 1992), leading to the demonstration that CD38 is actually a bifunctional enzyme with both extracellular ADP-ribosyl cyclase and cADPR hydrolase extracellular activity (Franco et al., 1993; Howard et al., 1993; Summerhill et al., 1993; Takasawa et al., 1993b; Koguma et al., 1994). However, the physiological significance of extracellular cADPR production remains unknown.

Extracellular NADase activity and the production of ADPR have been reported in rat brain synaptosomes (Snell et al., 1984). Because it is now known that NAD is the enzymatic precursor of cADPR, and ADPR the immediate product of its degradation (Clapper et al., 1987), and because several NAD glycohydrolases have been identified as ADP-ribosyl cyclases (Kim et al., 1993), we postulated that the synaptosomal enzyme might be an extracellular ADP-ribosyl cyclase as well. In the present study, we sought to demonstrate and characterize the synthesis of cADPR from NAD in rat cortical cultures, expecting to find an extracellular cyclase activity localized to neurons. The evidence presented here demonstrates the presence of an extracellular ADP-ribosyl cyclase activity associated with astrocytes in cortical cultures. 


\section{MATERIALS AND METHODS}

Tissue culture. Three kinds of embryonic rat cortical cell cultures were used for this study. Astrocyte-rich (AR) cultures contain 90\% astrocytes and $10 \%$ neurons. Neuron-enriched/astrocyte-poor (AP) cultures contain $20 \%$ astrocytes and $80 \%$ neurons. Astrocyte cultures do not contain any neurons, but may include small numbers of other cell types such as oligodendrocytes. AR and AP cultures derived from embryonic Sprague Dawley rats (Charles River Laboratories, Wilmington, MA) were prepared as described previously (Rosenberg, 1991). Tissue was harvested from 16-d-old embryos, dissociated with $0.027 \%$ trypsin and plated on poly-L-lysine- (AP) or collagen and poly-L-lysine- (AR) coated glass coverslips in $35 \mathrm{~mm}$ dishes (5 coverslips/dish) or in coated wells in 24-well plates (Costar, Cambridge, MA). The growth medium was 8:1:1 DMEM/ Ham's F-12/heat-inactivated iron-supplemented calf serum (Hyclone) containing glutamine ( $2 \mathrm{mM})$, HEPES (25 mM), glucose (25 mM), penicillin $(24 \mathrm{U} / \mathrm{ml})$, and streptomycin $(24 \mu \mathrm{g} / \mathrm{ml})$. AR cultures were inhibited with cytosine arabinoside $(5 \mu \mathrm{M})$ after $15 \mathrm{~d}$ for $72 \mathrm{hr}$ and maintained with three medium changes a week at $37^{\circ} \mathrm{C}$ and $5 \% \quad \mathrm{CO}_{2} / 95 \%$ air using heat-inactivated iron-supplemented calf serum. AP cultures were produced by inhibiting after $4 \mathrm{~d}$ for $48 \mathrm{hr}$ and replacing the medium on day 7 with AP medium (Rosenberg, 1991). This medium was not subsequently changed in AP cultures to maximize survival, and the cultures were placed on water-saturated filter paper pads to prevent water loss. Astrocyte cultures were made as described previously (Levison and McCarthy, 1991). In brief, cerebral cortex tissue was harvested from neonatal rat pups and mixed glial cultures prepared. Tissue was dissociated with $2.5 \%$ trypsin and triturated in Basal Medium Eagle's supplemented with $10 \%$ bovine calf serum (Hyclone A-2151-L) (BME-C), centrifuged $10 \mathrm{~min}$ at $100 \times g$, resuspended in BME-C, plated in tissue culture flasks, and grown for $12 \mathrm{~d}$ at $37^{\circ} \mathrm{C}$ with media changed after $3 \mathrm{~d}$ and every $2 \mathrm{~d}$ thereafter. Astrocyte cultures then were prepared from the mixed cultures. Other cell types were removed by shaking at $260 \mathrm{rpm}$ for $1.5 \mathrm{hr}$ at $37^{\circ} \mathrm{C}$, removing the medium, and rinsing twice with $\mathrm{BME}$ and once with a divalent cation-free saline, $\mathrm{pH} 7.3$, composed of (in mM): glucose 11, HEPES 20.2, trisodium citrate 10.2, $\mathrm{KCl} 4, \mathrm{NaCl} 110$, plus $2 \mathrm{mg} / \mathrm{l}$ phenol red (GHCKS). The adherent astrocyte cells then were dissociated with $0.25 \%$ trypsin in GHCKS. BME-C was added to inactivate the trypsin, and the suspension was centrifuged at $100 \times g$ for $10 \mathrm{~min}$. Supernatant was discarded and cells were resuspended in BME-C and plated on coverslips in dishes or in wells as for AR cultures. The astrocyte cultures then were maintained with three medium changes per week.

The age of the cultures used in experiments ranged from 21 to $35 \mathrm{~d}$ for $\mathrm{AR}$ and $\mathrm{AP}$ cultures, and 12 (after reaching confluence) to $70 \mathrm{~d}$ for astrocytes.

Media. Complete HBSS was from Sigma (St. Louis, MO). Calcium-free HBSS was prepared by supplementing calcium-, magnesium-, and bicarbonate-free HBSS with anhydrous magnesium sulfate $(0.098 \mathrm{gm} / \mathrm{l})$ and sodium bicarbonate $(0.35 \mathrm{gm} / \mathrm{l})$.

$N A D$ incubation experiments. Cultures were incubated with wells $(0.25$ or $0.5 \mathrm{ml})$ or with dishes $(1.3 \mathrm{ml}$ or $1.5 \mathrm{ml})$ of HBSS at room temperature or with agitation at $37^{\circ} \mathrm{C}$ for up to $120 \mathrm{~min}$. Initially, in some experiments, calcium-free HBSS was used. Collected media were replaced with HBSS [for monitoring the effect of the incubation conditions on cells by microscopy and lactate dehydrogenase (LDH) assays] or with $2 \%$ SDS (for protein assays).

When samples from experiments done in complete HBSS were assayed for calcium-releasing activity in the sea urchin egg homogenate bioassay, medium calcium was removed after incubation by shaking sample with Chelex 100 resin $(50 \mathrm{mg} / \mathrm{ml})$ (Bio-Rad, Hercules, CA) for $1 \mathrm{hr}$, centrifuging $1 \mathrm{~min}$ at 12,000 $\mathrm{rpm}$, and transferring the supernatant to a fresh tube.

HPLC assays. A $3.9 \times 150 \mathrm{~mm}$-Bondapak $\mathrm{C}_{18}$ reverse-phase column (Waters, Milford, MA) was connected behind a $5 \times 50$-mm PL SAX-100 strong anion exchange column (Polymer Laboratories) with an appropriate guard cartridge protecting each column (Kim et al., 1993; Lee et al., 1993). Initial experiments were performed with ammonium formate $(0.1$ $\mathrm{M}), \mathrm{pH}$ adjusted to 4.0 with formic acid $(0.5 \mathrm{ml} / \mathrm{min})$. Detection was by absorbance at $260 \mathrm{~nm}$. The following retention times were observed: cADPR, $6.2 \mathrm{~min}$; AMP, $9.4 \mathrm{~min}$; ADPR, $10.6 \mathrm{~min}$; NAD, $15.2 \mathrm{~min}$; and adenosine, $20.4 \mathrm{~min}$.

Subsequently, for the studies of cADPR hydrolytic activity, we used an ammonium formate gradient $(67.6-250 \mathrm{~mm})$, with a flow rate of 0.8 $\mathrm{ml} / \mathrm{min}$. From 0 to $6 \mathrm{~min}, 67.6 \mathrm{~mm}$ ammonium formate was maintained, then ammonium formate was increased to $250 \mathrm{~mm}$ over the next $12 \mathrm{~min}$. The column was taken from $100 \% 250 \mathrm{~mm}$ to $100 \% 67.6 \mathrm{~mm}$ ammonium formate over the next minute and then equilibrated from 19 to $25 \mathrm{~min}$ in $67.6 \mathrm{~mm}$ ammonium formate before the next sample was applied. Sample volume was $50 \mu \mathrm{l}$. Guanosine $(100 \mu \mathrm{M})$ was added to each sample as an internal standard, and for each substance measured, external standards were incorporated into each run. Quantitation was achieved using Beckman System Gold software by comparing the peak height of each substance being measured with the peak height of the internal standard in each sample, and comparing the values obtained with standard curves constructed of ratios of external standards with the internal standard. The following retention times were observed in this system: cADPR, $4.4 \mathrm{~min}$; guanosine, $8.4 \mathrm{~min}$; and ADPR, $12 \mathrm{~min}$.

Preparation of sea urchin egg homogenates. The protocol of Dargie et al. (1990) was followed. Lytechinus pictus sea urchins (Marinus, Long Beach, $\mathrm{CA})$ were injected intracoelomically with $\mathrm{KCl}(0.5 \mathrm{M})$ to induce spawning, and eggs were collected into artificial seawater (ASW) composed of (in $\mathrm{mM}$ ): $\mathrm{NaCl} 460, \mathrm{MgCl}_{2} 27, \mathrm{MgSO}_{4} 28, \mathrm{CaCl}_{2} 10, \mathrm{KCl} 10, \mathrm{NaHCO}_{3} 2.5, \mathrm{pH}$ adjusted to 8.0 with $\mathrm{NaOH}$. Approximately $50 \mathrm{ml}$ of eggs was collected from 25 females, and a sample was tested to confirm fertilizability by sperm. Eggs were dejellied by exposure to ASW, pH 5, and washed once in ASW, $\mathrm{pH}$ 8.0, twice in calcium-free, EGTA-supplemented ASW [as above, but with no $\mathrm{CaCl}_{2}$, and $\mathrm{NaCl}$ increased to 470 mM plus EGTA (1 $\mathrm{mM})$ ], twice in calcium-free ASW, and once in intracellular medium (ICM) composed of (in $\mathrm{mM}$ ): potassium gluconate 250, $N$-methylglucamine 250, HEPES 20, $\mathrm{MgCl}_{2} 1, \mathrm{pH}$ 7.2). Eggs were spun down $1 \mathrm{~min}$ at $1000 \mathrm{rpm}$ and supernatant discarded after each washing. The final volume after compaction during washing was $20 \mathrm{ml}$. The eggs were resuspended in ICM $(150 \mathrm{ml})$ freshly supplemented with leupeptin $(25$ $\mu \mathrm{g} / \mathrm{ml})$, aprotinin $(20 \mu \mathrm{g} / \mathrm{ml})$, creatine phosphokinase $(4 \mathrm{U} / \mathrm{ml})$, phosphocreatine $(8 \mathrm{mM})$, soybean trypsin inhibitor $(100 \mathrm{~g} / \mathrm{ml})$, and ATP $(1 \mathrm{~mm})$. The egg suspension was homogenized in a Dounce homogenizer with type A Teflon pestle (Thomas cat \# 3431D76) and placed on ice. The homogenate was centrifuged $10 \mathrm{sec}$ at $14,000 \mathrm{rpm}$ in an Eppendorf microfuge and the supernatant containing calcium-storing microsomes transferred to fresh tubes $(1 \mathrm{ml} /$ tube $)$, frozen, and stored at $-70^{\circ} \mathrm{C}$. These stocks are referred to as $10 \%$ egg homogenates.

Calcium-release bioassay. A modified version of the protocol of Galione et al. (1993) was used. For each day's assays, a fresh tube of $10 \%$ homogenate was thawed at $20^{\circ} \mathrm{C}$, diluted $50 \%$ with supplemented ICM containing phosphocreatine $(10 \mathrm{~mm})$, creatine phosphokinase $(10 \mathrm{U} / \mathrm{ml})$, ATP $(1.0 \mathrm{~mm})$, oligomycin $(1 \mu \mathrm{g} / \mathrm{ml})$, antimycin $(1 \mu \mathrm{g} / \mathrm{ml})$, and $\mathrm{NaN}_{3}(1$ $\mathrm{mm}$ ), and incubated $1 \mathrm{hr}$ at $20^{\circ} \mathrm{C}$. The dilution and incubation were repeated two more times, and the fluorescent calcium indicator Fluo 3 was added to $3 \mu \mathrm{M}$ after the final dilution. The final concentration of homogenate was $1.25 \%$.

Fluorimetry was done in a Hitachi F-2000 fluorescence spectrophotometer set for $490 \mathrm{~nm}$ excitation and $535 \mathrm{~nm}$ emission wavelengths with both slits at $5 \mathrm{~nm}$. Preincubated homogenate $(0.25 \mathrm{ml})$ was used for each assay. The homogenate was placed in a $1.0 \times 0.5-\mathrm{mm}$ glass cuvette, stirred continuously with a magnetic stirbar, and maintained at $20^{\circ} \mathrm{C}$ with a circulating water bath. Injections (1/100 volume, $2.5 \mu \mathrm{l})$ were made with a Hamilton glass syringe after baseline fluorescence was established, usually at 30 or $50 \mathrm{sec}$. For measurement of cADPR in experimental samples, standard curves of response to cADPR standards in incubation media based on initial rate of fluorescence increase were constructed.

Fluorometric assay for ADP-ribosyl cyclase. A sensitive assay for ADPribosyl cyclase was implemented based on the work of Graeff et al. (1994, 1996) showing that nicotinamide guanine dinucleotide (NGD) is a substrate for the enzyme, and that the product cyclic guanosine diphosphoribose (cGDP-ribose) is fluorescent and not readily hydrolyzed by cADPR hydrolase. We first verified by HPLC that exposure of NGD to astrocyte cultures produced only a single fluorescent peak, using excitation at $300 \mathrm{~nm}$ and monitoring emission through a $>390 \mathrm{~nm}$ long-pass filter. For the actual assay, cultures were washed three times with HBSS plus BSA $(0.1 \%)$, and then incubated with NGD (100 $\mu \mathrm{M})$ (Sigma) in Earle's balanced salt solution (EBSS) at $37^{\circ} \mathrm{C}$ for selected intervals of time, after which the medium was removed and assayed by measuring fluorescence in the Hitachi instrument using $300 \mathrm{~nm}$ excitation and 410 emission monochromator settings.

LDH assay. LDH was assayed by measuring the rate of disappearance of nicotinamide-adenine dinucleotide (NADH) added to samples in the presence of pyruvate, following published methods (Koh and Choi, 1987; Klingman et al., 1990). Sample medium $(25-50 \mu \mathrm{l})$ was added to $240 \mu \mathrm{l}$ of NADH $(113 \mu \mathrm{M})$ in phosphate buffer. Reaction was begun by adding $10 \mu \mathrm{l}$ of pyruvate $(22.7 \mathrm{~mm})$, and absorbance was determined at $340 \mathrm{~nm}$ 
over a period of 4 min using a kinetic plate reader (Molecular Devices, Menlo Park, CA).

Protein assay. A bicinchoninic acid reagent protein assay (Pierce Chemical Company, Rockford, IL) kit using a bovine serum albumin (BSA) standard was used to assay the amount of protein present in wells and dishes used for experiments. Postexperiment cultures solubilized with $2 \%$ SDS and stored at $4^{\circ} \mathrm{C}$ were used. Data obtained were used to calculate ADP-ribosyl cyclase and cADPR hydrolase activity per milligram of protein. For $35 \mathrm{~mm}$ dishes, protein content was $0.496 \pm 0.08 \mathrm{mg}$ for AP cultures ( $n=6$ and 2 culture dates), $0.96 \pm 0.17 \mathrm{mg}$ for astrocyte cultures ( $n=8$ and 3 culture dates), and $1.19 \pm 0.15 \mathrm{mg}$ for AR cultures $(n=12$ and 5 culture dates).

For experiments measuring hydrolase activity, $12 \mathrm{~mm}$ glass coverslip cultures in wells were used to decrease the volume of medium required for the experiment. In these cultures, the protein was determined using the Bradford dye-binding protein assay (1976) with a BSA standard (Bio-Rad). In these experiments, the cell layer was solubilized in $\mathrm{NaOH}$ $(0.1 \mathrm{M})$. Protein content was $54 \pm 7$ and $99 \pm 19 \mu \mathrm{g}$ for astrocyte and AR cultures, respectively.

Data analysis. Statistical variation was determined by calculating SD in multiple data points from a single experiment or SEM where data from multiple experiments were pooled. Statistical comparisons were performed using Student's $t$ test or ANOVA followed by the Tukey-Kramer test for multiple comparisons, using the Instat2 program from Graphpad Software.

Materials. All reagents and drugs were obtained from Sigma except $\mathrm{IP}_{3}$ and heparin (Calbiochem, La Jolla, CA), HEPES, and ATP (Boehringer Mannheim, Indianapolis, IN), Chelex 100 (Bio-Rad), Fluo 3 (Molecular Probes, Eugene, OR), and methanol (Fisher, Orangeburg, NY). cADPR was purchased both from Amersham (Arlington Heights, IL) and Sigma.

\section{EXPERIMENTAL RESULTS}

Three types of cultures differing in cell composition were used: neuron-enriched/AP (20\% astrocytes, $80 \%$ neurons), AR $(90 \%$ astrocytes, $10 \%$ neurons), and astrocyte (100\% astrocytes). AR cultures contain $\sim 30$ times the number of astrocytes as AP cultures (Rosenberg, 1991). Both AP and AR cultures are rich in synapses, which are exposed to the extracellular medium in AP cultures but sequestered by a near-confluent layer of astrocytes in AR cultures (Harris and Rosenberg, 1993).

\section{Implementation of the egg homogenate calcium-release bioassay}

We implemented the sea urchin egg homogenate bioassay developed by Lee and colleagues (Clapper et al., 1987) and modified by Galione et al. (Galione et al., 1993) to look for extracellular ADP-ribosyl cyclase activity associated with neurons and astrocytes in culture. Representative traces and a typical standard curve of Fluo 3 fluorescence increase caused by calcium release in response to injected authentic cADPR are shown in Figure 1, $A$ and $B$. The homogenate also released calcium in response to $\mathrm{IP}_{3}$ $(1 \mu \mathrm{M})$ (Fig. 1C). Calcium release in response to NAD $(10 \mu \mathrm{M})$ was low and delayed (Fig. 1D) as reported previously (Clapper et al., 1987). This difference in the kinetic characteristics of homogenate response to $\mathrm{CADPR}$ and to NAD made it possible to distinguish between them at NAD concentrations up to $1 \mathrm{~mm}$ in the medium exposed to cells (10 $\mu \mathrm{M}$ final concentration in homogenate). We also confirmed previous observations that $\mathrm{IP}_{3}(1$ $\mu \mathrm{M})$ desensitized the homogenate to subsequent injections of $\mathrm{IP}_{3}$, but not to cADPR (100 nM), and that, conversely, cADPR desensitized the homogenate to cADPR but not to $\mathrm{IP}_{3}$ (Clapper et al., 1987; Dargie et al., 1990).

\section{Demonstration of cADPR formation in cultures using bioassay}

AR well cultures were incubated $30 \mathrm{~min}$ in calcium-free HBSS containing NAD $(100 \mu \mathrm{M})$ (calcium-free medium was used initially, because medium samples were ultimately to be tested for calcium-releasing activity). A distinct calcium-releasing effect was caused by the $100 \mu \mathrm{M}$ NAD incubation medium both with $15 \mathrm{~min}$ (Fig. 2, trace 2) and $30 \mathrm{~min}$ (Fig. 2, trace 3) exposure to cultures that was different from the response observed with the control solution (Fig. 2, trace 1).

We found that media samples retained some calcium-releasing activity in homogenate desensitized to both cADPR and $\mathrm{IP}_{3}$, indicating the presence of a calcium-releasing agent other than these two compounds. The source of this residual calciumreleasing activity in the incubation samples was then investigated and was found to be nicotinamide, which previously has been shown to have calcium-releasing activity in the sea urchin egg homogenate bioassay (Clapper et al., 1987). We found that nicotinamide $(100 \mu \mathrm{M})$ produced an increase in fluorescence of $8 \pm$ 1.2 (mean $\pm \mathrm{SEM}$ ) fluorescence units equivalent to the increase produced by $2.7 \pm 0.3 \mathrm{nM}$ cADPR ( 24 determinations in 3 separate experiments). Taking this information into account, the experimental protocol was modified. The incubations were carried out in $35 \mathrm{~mm}$ dishes instead of 24-well plates to increase the tissue to volume ratio (wells contain $\sim 0.3 \mu \mathrm{g}$ protein $/ \mu \mathrm{l}$, based on minimal medium volume at $300 \mu \mathrm{l}$; dishes contain $\sim 0.6 \mu \mathrm{g}$ protein/ $\mu \mathrm{l}$ based on minimal medium volume of $1.5 \mathrm{ml}$ ), the NAD concentration was increased to $1 \mathrm{~mm}$, and incubation time was increased to $60 \mathrm{~min}$. These changes substantially increased the amount of calcium-releasing activity produced by the cultures. Two injections of nicotinamide $(100 \mu \mathrm{M})$ were used to eliminate the response to nicotinamide present in the media samples (which could at most be $1 \mathrm{~mm}$ in the media, diluted to $10 \mu \mathrm{M}$ in the homogenate). In fact, nicotinamide $(10 \mu \mathrm{M})$ produced no significant effect on the fluorescence of the homogenate after previous treatment with nicotinamide $(100 \mu \mathrm{M}$. Nicotinamide was therefore routinely injected before assay of media samples.

Astrocyte and AR media samples elicited calcium release in homogenate pretreated with heparin (to block $\mathrm{IP}_{3}$ responses) and to nicotinamide (Figs. $3 A, 4 A$ ), indicating the presence of a calcium-mobilizing agent other than $\mathrm{IP}_{3}$ and nicotinamide. Response to astrocyte and AR samples was almost completely abolished in homogenates desensitized to nicotinamide and to cADPR (Figs. $3 B, 4 B$ ), indicating that the sample activity was attributable to nicotinamide and to cADPR only. The astrocyte and AR samples also desensitized homogenate to further calcium release by cADPR but not to calcium release by $\mathrm{IP}_{3}$ (Figs. $3 C, 4 C$ ). In summary, once the effect of nicotinamide was suppressed, culture media samples were shown to desensitize homogenate to cADPR and, conversely, cADPR was shown to desensitize homogenate to the media samples. These results strongly support the hypothesis that cADPR was present in the media of cultures incubated with NAD. A time course of the synthesis of cADPR from NAD in astrocyte cultures in medium with and without calcium is shown in Figure 5. Maximal extracellular concentrations of cADPR were attained by $\sim 60 \mathrm{~min}$, and no evidence of clearance of $\mathrm{cADPR}$ was observed.

\section{Determination of the specific activity of cADPR synthesis in cortical cultures}

To investigate whether cADPR synthesis activity was localized to neurons or astrocytes, we determined the ADP-ribosyl cyclase activity in AP, AR, and astrocyte cultures. Cultures were incubated with NAD (1 mM) in HBSS (with calcium), and samples of the media were assayed for calcium- releasing activity at $60 \mathrm{~min}$, after calcium had been removed from the medium by the use of Chelex ionexchange resin. AR and astrocyte media samples appeared to have 


\section{A}

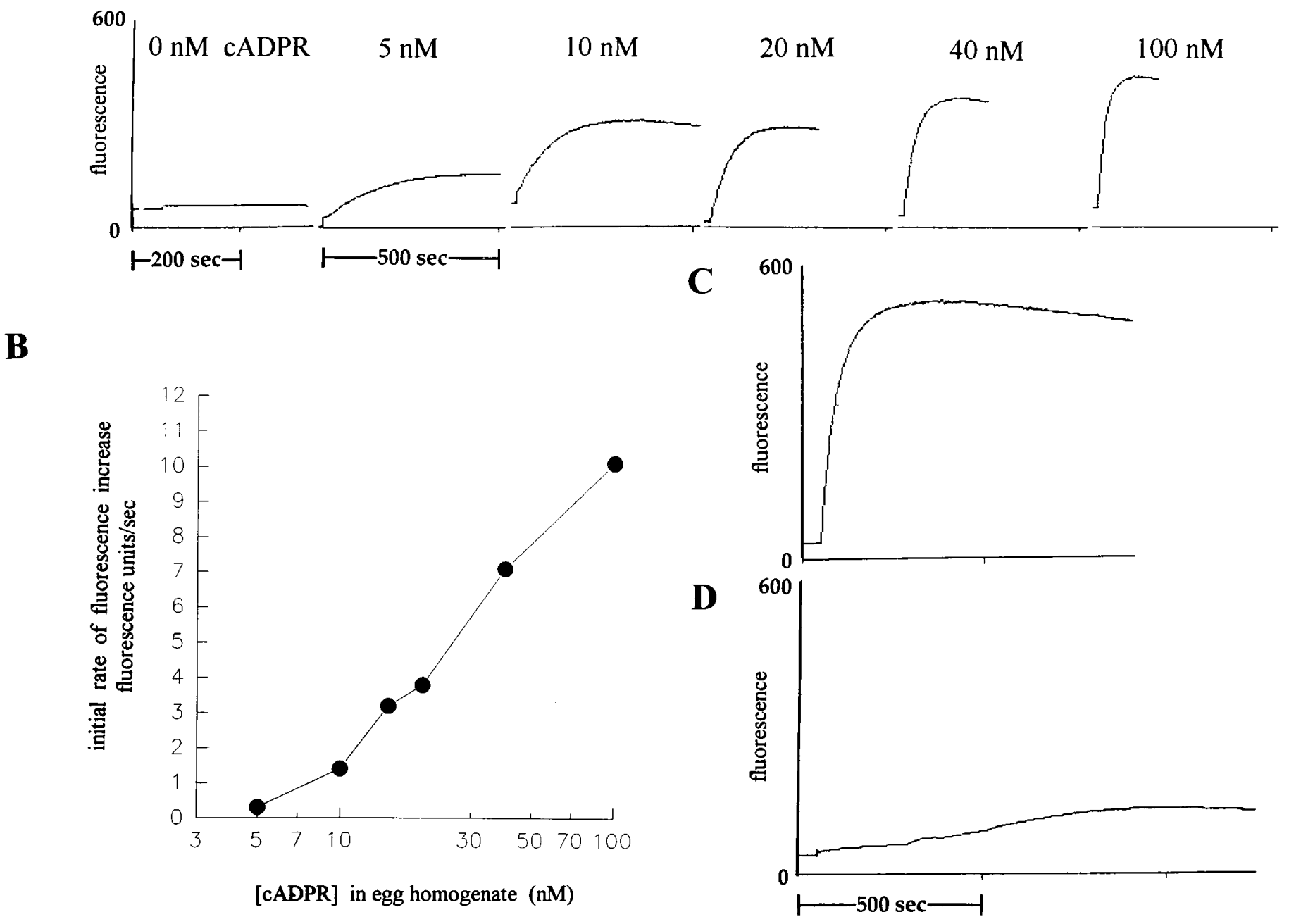

Figure 1. Calcium release by cADPR and $\mathrm{IP}_{3}$ in sea urchin egg homogenates. $A$, Representative traces of Fluo 3 fluorescence increase attributable to calcium release in egg homogenate injected with authentic cADPR standards ( $0-100 \mathrm{~nm}$ final concentrations). Injections were performed at 50 sec. The horizontal axes show time, tick $=500 \mathrm{sec}$, except for the far left trace where tick $=200 \mathrm{sec}$. Vertical axis $=600$ fluorescence units. $B$, Standard curve of the initial rate of fluorescence increase (measured at $20 \mathrm{sec}$ ) in egg homogenate injected with authentic cADPR standards. $C$, Representative trace of Fluo 3 fluorescence increase attributable to calcium release in egg homogenate injected with $\mathrm{IP}_{3}$ (final concentration $1 \mu \mathrm{M}$ ). Time axis tick $=500$ sec; vertical axis $t i c k=600$ fluorescence units. $D$, Representative trace of Fluo 3 fluorescence after injection of NAD (10 $\mu \mathrm{M}$ final concentration).

comparable activity: $0.84 \pm 0.06 \mathrm{nmol} \mathrm{cADPR} / \mathrm{mg}$ protein/hr for astrocyte cultures $(n=3$; mean \pm SEM) and $0.96 \pm 0.18 \mathrm{nmol}$ $\mathrm{cADPR} / \mathrm{mg}$ protein $/ \mathrm{hr}(n=5$; mean \pm SEM) for AR cultures (Table 3 ). No calcium-releasing activity distinguishable from that caused by the NAD present was observed in the AP cultures $(n=2)$.

Because AP cultures contain less protein than astrocyte cultures or AR cultures, we were concerned that the production of cADPR by these cultures might be significant but below the level of detection of the bioassay. To pursue this, we used a sensitive fluorometric assay based on the work of Graeff et al. $(1994,1996)$ that showed that NGD is a substrate for ADP-ribosyl cyclase, yielding a fluorescent product, cGDPR. Figure 6 shows data from one representative experiment of three that were performed. When astrocyte cultures and AR cultures were incubated with NGD $(100 \mu \mathrm{M})$, which is not fluorescent, they caused a robust time-dependent increase in fluorescence in the extracellular medium, which is attributable to the accumulation of cGDPR (Graeff et al., 1994). In contrast, AP cultures caused a very small increase in the fluorescence of the medium that was significantly different $(p<0.05)$ from the control values [NGD $(100 \mu \mathrm{M})$ in EBSS that was not exposed to cultures] in two of three experiments. In three experiments, the mean increase in fluorescence intensity in the medium exposed to AP cultures at 60 min was $4.4 \pm 0.2 \%$ (mean \pm SEM) of the fluorescence intensity appearing in the medium exposed to AR cultures and $4.8 \pm 0.4 \%$ of the fluorescence intensity appearing in the medium exposed to astrocyte cultures. In these three experiments, the protein content was $42 \pm$ $8,177 \pm 12$, and $154 \pm 6 \mu \mathrm{g}$ in the $\mathrm{AP}, \mathrm{AR}$, and astrocyte cultures, respectively.

\section{Evidence for an extracellular localization of ADP- ribosyl cyclase activity}

The fact that formation of cADPR could be demonstrated by adding NAD to the extracellular medium suggested that ADPribosyl cyclase activity associated with cortical cultures was itself an extracellular enzyme activity. To pursue this further, we ex- 


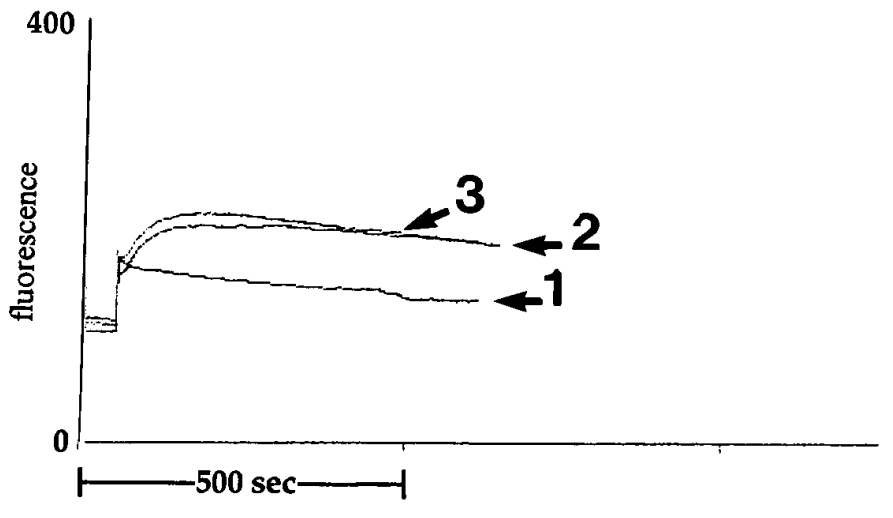

Figure 2. Production of calcium-releasing activity in media of AR cultures incubated with NAD. AR well cultures were incubated at room temperature with calcium-free HBSS buffer containing NAD $(100 \mu \mathrm{M})$. Samples were assayed for calcium-releasing activity in sea urchin egg homogenates with Fluo 3 fluorescence detection. Horizontal axis: tick = $500 \mathrm{sec}$. Vertical axis tick $=400$ fluorescence units. Trace 1, HBSS + NAD control (no exposure to culture); trace 2, 15 min incubation of culture with HBSS + NAD; trace 3, 30 min incubation of culture with HBSS + NAD.

posed cultures to NAD (1 mM) in the extracellular medium with and without $0.25 \%$ Triton X-100, and compared ADP-ribosyl cyclase activity and LDH in the extracellular medium (Table 1). The presence of Triton X-100 in the medium increased the LDH activity $31.3 \pm 13$ fold $(n=3)$ without significant effect on the ADP-ribosyl cyclase activity.

\section{Demonstration of CADPR production in astrocyte cultures by HPLC}

We sought to confirm the production of cADPR in astrocyte cultures directly by HPLC. Astrocyte dishes and wells were incubated at $37^{\circ} \mathrm{C}$ with complete HBSS containing NAD (1 mM) and media samples were assayed using a two-column HPLC system (Kim et al., 1993) (see Materials and Methods). A peak, which was absent in media controls and in media of cultures incubated with HBSS only, appeared at the retention time for cADPR of 6.2 min (Fig. 7A, upper trace, downward arrow).

To confirm the identity of this peak as cADPR, samples were placed in boiling water for $30 \mathrm{~min}$, which converts cADPR quantitatively to ADPR but does not affect ADPR (Kim et al., 1993). This treatment degraded the $6.2 \mathrm{~min}$ peak in the medium sample (compare upper trace with lower trace in Fig. $7 A$ at downward arrow). Furthermore, we confirmed that authentic ADPR was unaffected by boiling (Fig. 7B, upper chromatogram), whereas authentic cADPR was quantitatively converted to ADPR by boiling (Fig. 7B, middle chromatogram). The elution of authentic cADPR before boiling is shown in Figure $7 \mathrm{~B}$, lower chromatogram). In addition, we verified that authentic cADPR coeluted with the putative cADPR (data not shown).

\section{cADPR hydrolysis in cortical cell cultures}

ADP-ribosyl cyclase activity has been reported to copurify with cADPR hydrolase activity in several different cell types, and particularly in mammalian cells with extracellular activity (Franco et al., 1993; Lee et al., 1993; Takasawa et al., 1993b), leading to the proposal that NADase is a bifunctional enzyme (Kim et al., 1993). We therefore investigated the presence of cADPR hydrolase activity in the cortical cultures. Cultures were incubated for $60 \mathrm{~min}$ at $37^{\circ} \mathrm{C}$ in HBSS containing cADPR $(300 \mu \mathrm{M})$, and media samples were assayed by HPLC. We found a small but significant decrease in the concentration of CADPR in the medium exposed
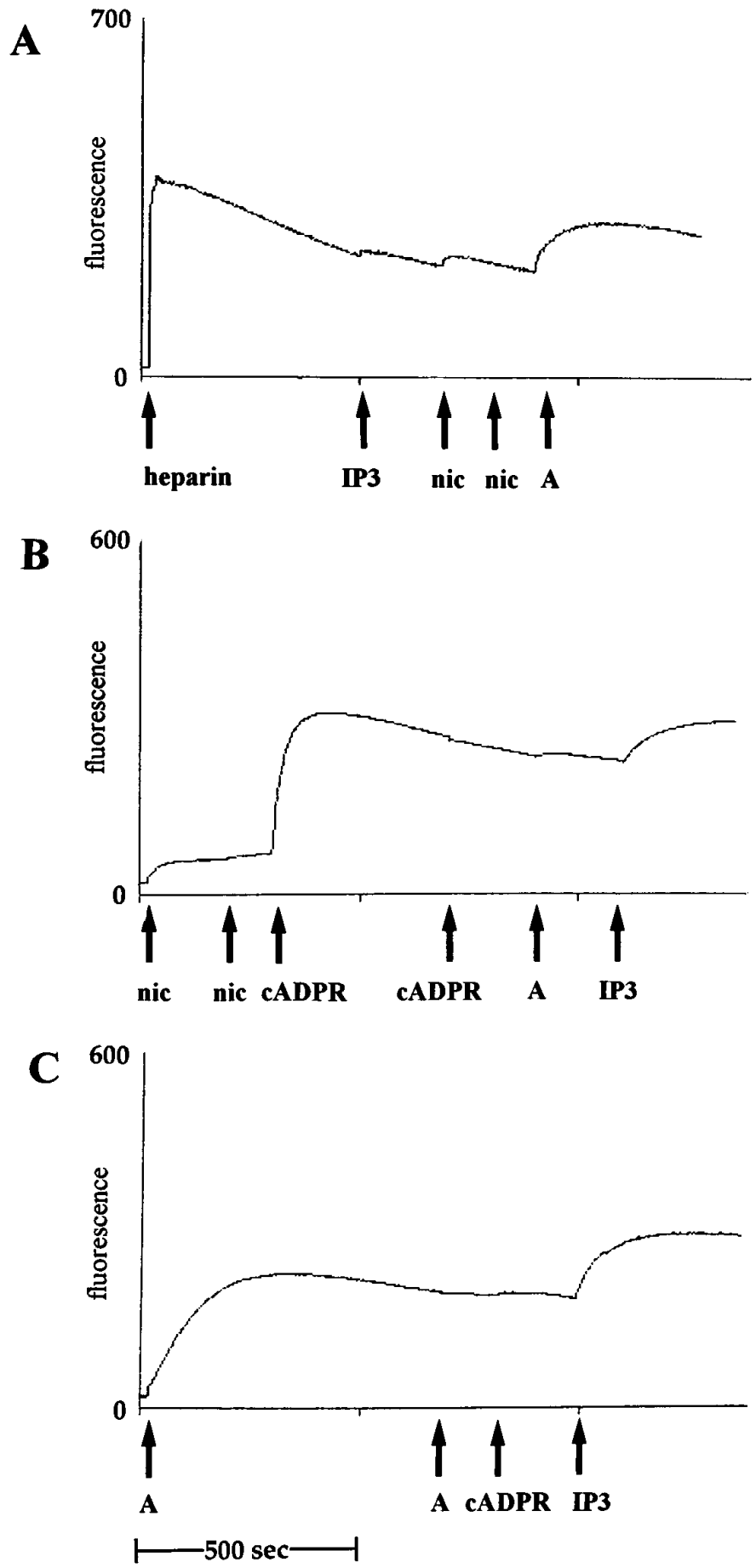

Figure 3. Positive identification of cADPR in media of astrocyte cultures incubated with $1 \mathrm{~mm}$ NAD. Astrocyte $(A)$ dish cultures were incubated 60 min at $37^{\circ} \mathrm{C}$ with calcium-free HBSS containing NAD (1 mM). Samples were assayed for calcium-releasing activity in egg homogenates desensitized to nicotinamide and to $\mathrm{IP}_{3}$ or cADPR. Time axis tick $=500 \mathrm{sec}$. $A$, Heparin $(250 \mu \mathrm{g} / \mathrm{ml}), \mathrm{IP}_{3}(1 \mu \mathrm{M})$, and nicotinamide $(2 \times 100 \mu \mathrm{M})$ did not desensitize egg homogenate to calcium-releasing activity in the astrocyte incubation medium $(A$ under arrow). $B$, Nicotinamide $(2 \times 100 \mu \mathrm{M})$ and cADPR $(2 \times 100 \mathrm{nM})$ almost completely desensitized egg homogenate to calcium-releasing activity in the astrocyte incubation medium. $C$, The astrocyte incubation medium desensitized egg homogenate to repeated injections of media and to cADPR $(100 \mathrm{nM})$ but not to $\mathrm{IP}_{3}(1 \mu \mathrm{M})$. 


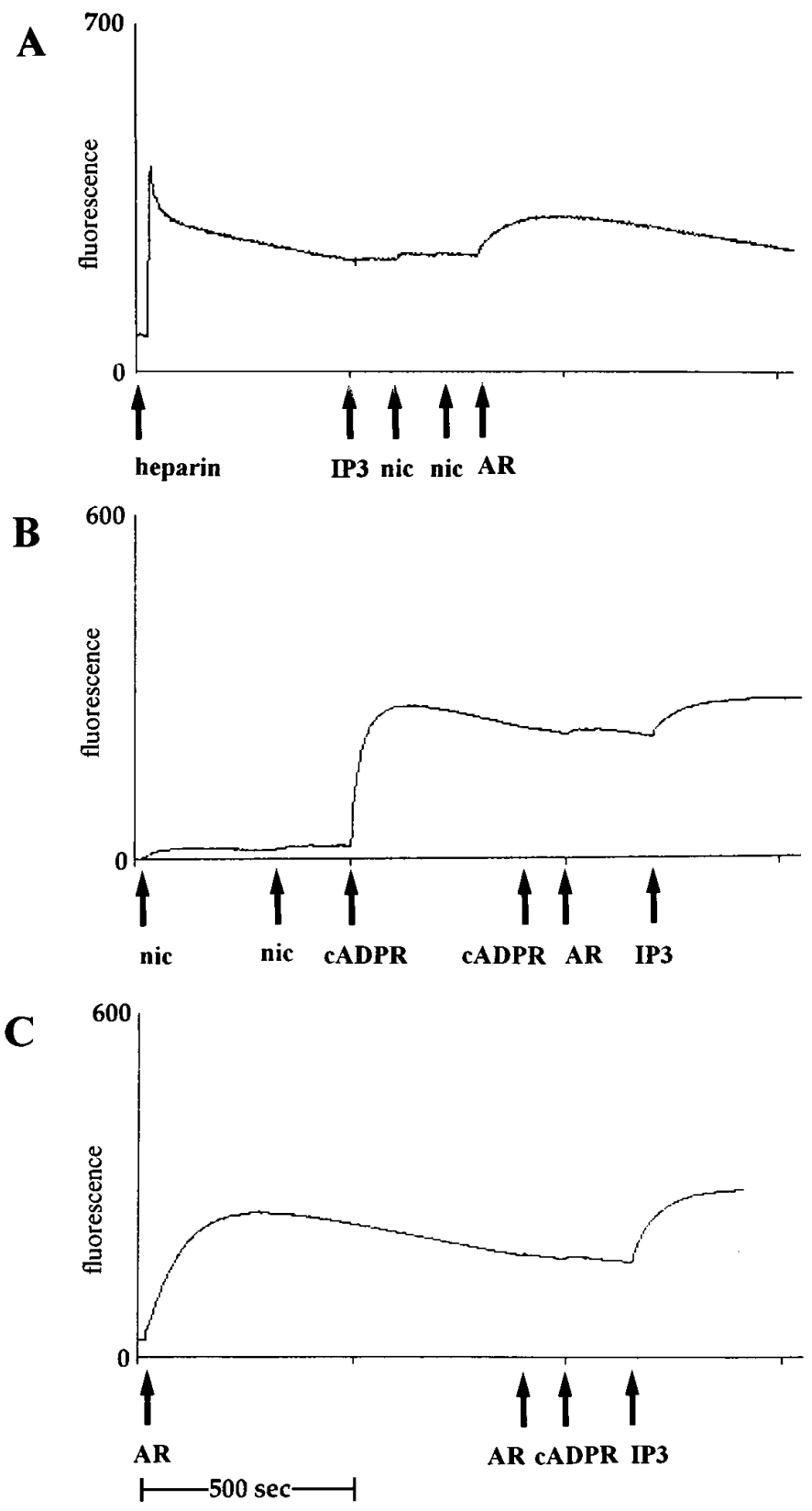

Figure 4. Positive identification of cADPR in media of AR cultures incubated with $1 \mathrm{~mm}$ NAD. Experimental protocol as in Figure 3. Time axis tick $=500 \mathrm{sec}$. $A$, Heparin $(250 \mu \mathrm{g} / \mathrm{ml}), \mathrm{IP}_{3}(1 \mu \mathrm{M})$, and nicotinamide $(2 \times 100 \mu \mathrm{M})$ did not desensitize egg homogenate to calcium-releasing activity in the AR incubation medium. $B$, Nicotinamide $(2 \times 100 \mu \mathrm{M})$ and cADPR $(2 \times 100 \mathrm{nM})$ almost completely desensitized egg homogenate to calcium-releasing activity in the AR incubation medium. $C$, The calciumreleasing activity in the AR incubation medium desensitized egg homogenate to itself and to CADPR (100 nM) but not to $\mathrm{IP}_{3}$.

to astrocyte and mixed cultures compared with medium that had been incubated under the same conditions but without cells (Table 2). These changes in cADPR concentration correspond to a rate of hydrolysis of cADPR of 167 and $111 \mathrm{nmol} / \mathrm{mg}$ protein/hr, respectively (Table 3 ). There was an expected concomitant although smaller increase in ADPR concentration that also was significant (Table 2). These changes in ADPR concentration correspond to a rate of hydrolysis of cADPR in the astrocyte and mixed cultures of 24 and $18 \mathrm{nmol} / \mathrm{mg}$ protein/hr, respectively,

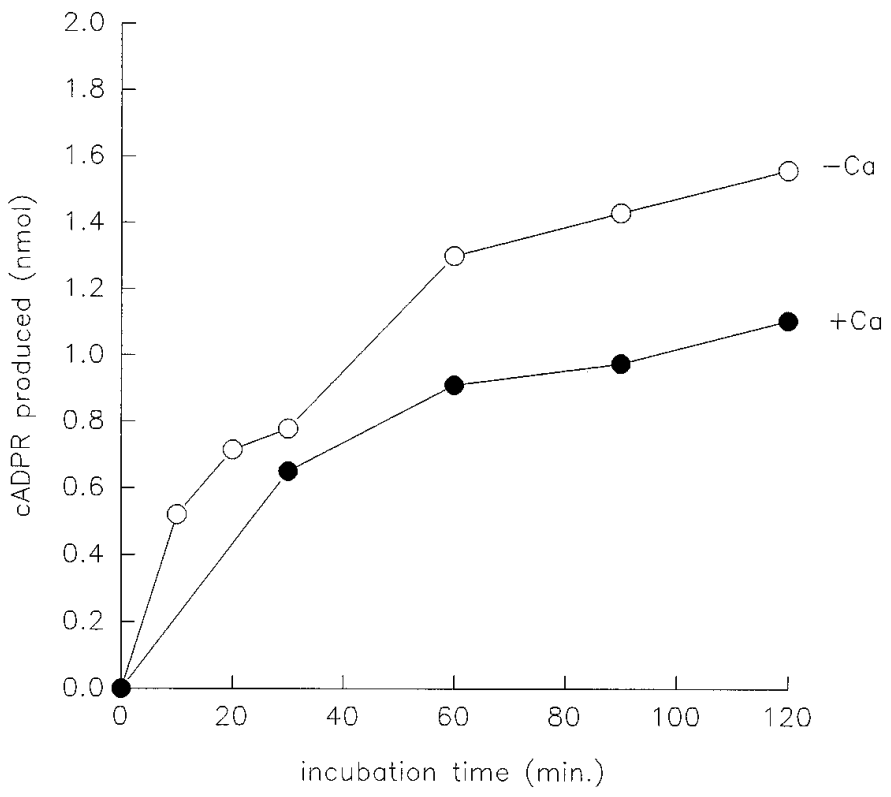

Figure 5. Representative time course of cADPR production in astrocyte cultures incubated with or without calcium. Astrocyte dish cultures were incubated at $37^{\circ} \mathrm{C}$ with complete (filled circles) or calcium-free (open circles) HBSS buffer containing NAD (1 mM). cADPR production was quantified by measurement of the initial rate of Fluo 3 fluorescence increase attributable to calcium mobilization in egg homogenate previously desensitized to nicotinamide. Calcium in HBSS was removed by treatment with Chelex before assay.

considerably less than that calculated on the basis of changes in cADPR concentration (Table 3). In media exposed to AP cultures, there was neither a significant decrease in CADPR nor an increase in ADPR, as expected given the absence of ADP-ribosyl cyclase activity in these cultures.

\section{DISCUSSION}

The objective of this study was to demonstrate, quantify, and localize ADP-ribosyl cyclase and cADPR hydrolase activity in rat cortical cultures. The evidence for ADP-ribosyl cyclase activity in cortical cell cultures presented in this study rests on the selective desensitization properties of the sea urchin egg homogenate bioassay and a demonstration of cADPR in media samples by HPLC. When sea urchin egg microsomes are exposed to either cADPR $(100 \mathrm{nM})$ or $\mathrm{IP}_{3}(1 \mu \mathrm{M})$, they become desensitized and no longer release calcium in response to subsequent injections of the same agent, but retain a response to the other agent. Injection with heparin $(250 \mu \mathrm{g} / \mathrm{ml})$ also results in desensitization to $\mathrm{IP}_{3}$. The desensitization criterion led us to rediscover the calcium-releasing activity of nicotinamide (Clapper et al., 1987), and made it possible to account for and almost completely eliminate residual non-cADPR and non- $\mathrm{IP}_{3}$ calcium-releasing activity in experimental samples. Homogenate desensitized to both nicotinamide and $\mathrm{IP}_{3}$ released calcium in response to media samples from $\mathrm{AR}$ and astrocyte cultures incubated with NAD (Figs. $3 A, 4 A$ ), whereas homogenate desensitized to nicotinamide and cADPR no longer did (Figs. 3B, 4B). Furthermore, multiple injections of media samples desensitized the homogenate to further calcium release by authentic cADPR, but not by $\mathrm{IP}_{3}$ (Figs. $3 C, 4 C$ ). These results provide strong evidence of the presence of CADPR in the extracellular medium.

We observed a large increase in fluorescence after heparin 


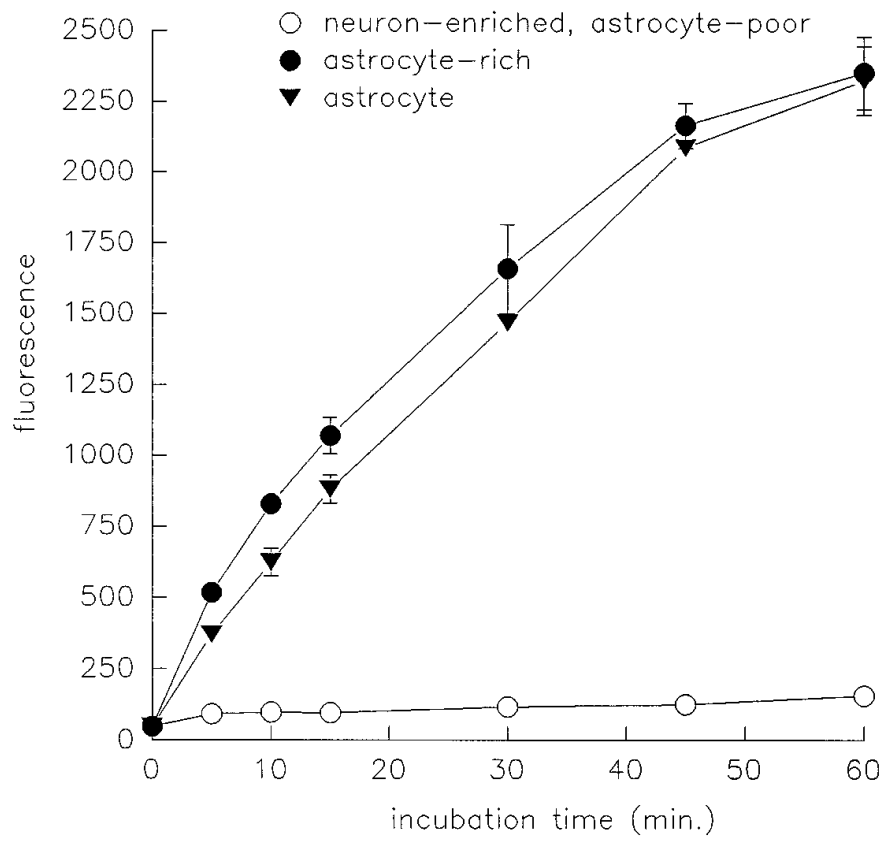

Figure 6. Comparison of ADP-ribosyl cyclase activity in astrocyte, AR cultures, and AP cultures by assaying conversion of NGD to the fluorescent compound cGDP-ribose. Cultures grown in 24-well plates were incubated with NGD $(100 \mu \mathrm{M})$ in EBSS at $37^{\circ} \mathrm{C}$ for selected intervals of time, after which medium was removed and assayed for the appearance of fluorescence emission at $410 \mathrm{~nm}$ with excitation at $300 \mathrm{~nm}$. Both astrocyte and AR cultures caused a time-dependent increase in fluorescence intensity. AP cultures caused an increase in fluorescence that was significantly greater than control, but at 60 min was only $\sim 5 \%$ of the intensity seen with astrocyte and AR cultures.

injection (Figs. $3 A, 4 A$ ). Heparin is known to activate ryanodine receptors in a calcium-dependent manner, and the fact that we saw a fluorescence increase with heparin suggests that the calcium concentration in the homogenate was high enough $(>20 \mathrm{~nm})$ to have permitted heparin-activated release of calcium mediated by ryanodine receptors (Ehrlich et al., 1994). The responses to the culture media were smaller after heparin injection (compare responses in Figs. $3 A, 4 A$ with responses in Figs. $3 C, 4 C$ ). It seems most likely that this difference is attributable either to to partial desensitization of the ryanodine receptor by heparin, to partial depletion of the cADPR-sensitive calcium stores, or to nonlinearity of the Fluo 3 fluorescence response.

Additional confirmation of the production of cADPR by cortical cultures was sought by HPLC. No cADPR was detected in NAD standards or in the media of cultures incubated with HBSS alone. A peak with the retention time characteristic of cADPR did

Table 1. Effect of permeabilization of cultures on extracellular ADPribosyl cyclase and lactate dehydrogenase activities

\begin{tabular}{llc} 
& $\begin{array}{l}\text { ADP-ribosyl } \\
\text { cyclase activity } \\
\text { (nmol/mg pro- } \\
\text { tein/hr) }\end{array}$ & $\begin{array}{l}\text { Lactate } \\
\text { dehydrogenase } \\
\text { activity } \\
(\mathrm{U} / \mathrm{ml} \text { medium })\end{array}$ \\
\hline HBSS & $1.25 \pm 0.06$ & $1.1 \pm 0.2$ \\
HBSS $+0.25 \%$ Triton X-100 & $1.19 \pm 0.04$ & $36.4 \pm 14.7$
\end{tabular}

AR cultures were incubated with 1 mm NAD in HBSS with or without $0.25 \%$ Triton $\mathrm{X}-100$ for $1 \mathrm{hr}$ at $37^{\circ} \mathrm{C}$ in a shaking water bath, after which medium samples were bioassayed for cADPR activity. Data represent mean \pm SEM from three separate experiments. appear in a time-dependent manner in media samples from cultures incubated with NAD, strongly suggesting the presence of cADPR (Fig. 7A). The specific susceptibility of the 6.2 min peak to boiling (Kim et al., 1993), analogous to the behavior of authentic cADPR but not ADPR (Fig. $7 A, B$ ), as well as coelution with authentic cADPR, offered additional proof of its identity as cADPR.

In summary, three different pieces of evidence support the identification of cADPR in the medium of cortical cultures incubated with NAD: (1) the medium caused release of calcium in sea urchin egg homogenates desensitized to nicotinamide and $\mathrm{IP}_{3}$, but not in homogenates desensitized to nicotinamide and cADPR; (2) the medium desensitized homogenate to further release of calcium by cADPR but not by $\mathrm{IP}_{3}$; (3) an HPLC peak is present in the medium that has the same retention time as cADPR. This peak is not present in medium of cultures incubated without $\mathrm{NAD}$, nor is it present in NAD; this peak is selectively degraded by boiling, which also degrades authentic cADPR but does not affect ADPR, and it coelutes with authentic cADPR.

The ADP-ribosyl cyclase activity appears to localize to astrocytes. No calcium release and therefore no detectable cADPR formation was observed in the medium of AP cultures incubated with NAD (1 mM). This result suggests that embryonic neurons in culture do not have detectable ADP-ribosyl cyclase activity. Previously, it has been shown that embryonic neurons in culture do not possess detectable $\beta$-adrenergic receptors (Trimmer et al., 1984), whereas adult cortical and hippocampal neurons clearly do (Madison and Nicoll, 1982, 1986a,b). Therefore, the absence of ADP-ribosyl cyclase activity from embryonic neurons in culture may be attributable to an effect of growing the cells in tissue culture or to a developmental phenomenon. In fact, CD38 has been demonstrated immunocytochemically in the cell bodies and dendrites of neurons in the adult human cerebellum and cerebral cortex (Mizuguchi et al., 1995).

The ADP-ribosyl cyclase activity in astrocytes of $0.84 \pm 0.06$ $\mathrm{nmol} \mathrm{cADPR} / \mathrm{mg}$ protein/hr determined in this study is lower than previously reported values of $4.5 \pm 0.1 \mathrm{nmol} / \mathrm{mg} / \mathrm{hr}$ for salamander brain, $20.6 \pm 2.8 \mathrm{nmol} / \mathrm{mg} / \mathrm{hr}$ for chick embryonic brain, $62.7 \pm 6.2 \mathrm{nmol} / \mathrm{mg} / \mathrm{hr}$ for dog brain (Lee and Aarhus, 1993 ), and $300 \mathrm{nmol} / \mathrm{mg} / \mathrm{hr}$ reported for pig brain (Gu and Sih, 1994). There are several possible explanations for this discrepancy. One is that the cited studies were performed using adult animals, and therefore a developmental difference might account for the difference in activity as well as for the apparent lack of activity associated with neurons, cited above. By this reasoning, the increase in activity seen in whole adult brain might be attributable to a developmental increase in activity associated with astrocytes or to the emergence of activity associated with neurons. Almost all of the activity seen in culture is extracellular, and thus it also is possible that with development, a significant increase in intracellular activity occurs. Furthermore, there may be significant regional differences in the expression of ADP-ribosyl cyclase activity in neurons and astrocytes in the brain, and cells other than neurons and astrocytes (e.g., oligodendrocytes, endothelial cells, microglia) might exhibit high activity. Finally, there may be significant species differences.

We directly demonstrated cADPR hydrolase activity in the cultures by incubating them with cADPR $(300 \mu \mathrm{M})$. Hydrolase activity has been found associated with cyclase activity in all other tissues except Aplysia, leading to the suggestion that mammalian NADase is a bifunctional enzyme (Kim et al., 1993). In previous studies, the cADPR hydrolase activity of the NADase CD38 was 

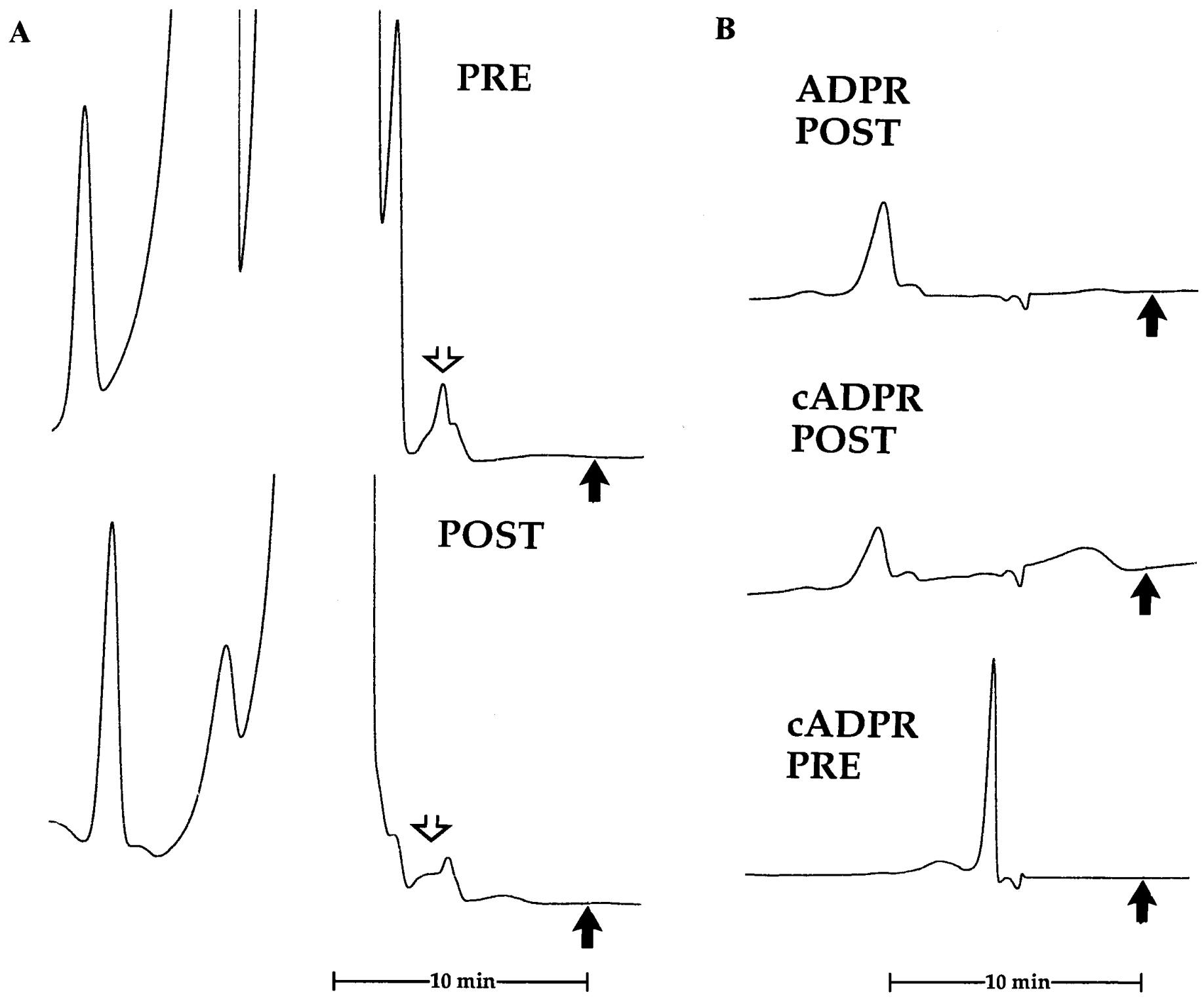

Figure 7. Confirmation by HPLC of cADPR production by astrocyte cultures. Astrocyte dish cultures were incubated with complete HBSS with NAD $(1 \mathrm{mM})$ at $37^{\circ} \mathrm{C}$ for $120 \mathrm{~min}$. Media samples $(50 \mu \mathrm{l})$ were run on a two-column HPLC system (PL-SAX column followed by a $\mathrm{C}_{18}$ reverse-phase column) (see Materials and Methods) and assayed by absorbance detection. The selective degradation of cADPR by boiling for 30 min was used as an additional test for cADPR. The solid upward arrows indicate the time of injection of sample. $A$, Degradation by boiling of $6.2 \mathrm{~min}$ peak in astrocyte incubation medium sample by boiling. Upper trace, Astrocyte medium sample (120 min incubation) before boiling. A peak is present at 6.2 min, indicated by downward open arrow, which is the retention time of cADPR. Lower trace, Astrocyte medium sample (120 min incubation) after boiling for 30 min. Boiling has removed the peak at $6.2 \mathrm{~min}$, indicated by downward open arrow. B. Boiling for $30 \mathrm{~min}$ degrades authentic cADPR to ADPR but does not affect ADPR. Upper trace, ADPR $(5 \mu \mathrm{M})$ standard after 30 min boiling. The retention time is 10.8 min, the value previously determined for unboiled ADPR. Middle trace, cADPR ( $2 \mu \mathrm{M})$ standard after boiling for $30 \mathrm{~min}$. The cADPR peak at $6.2 \mathrm{~min}$ is no longer visible; instead, a peak has appeared at $10.8 \mathrm{~min}$, which is the ADPR retention time. Bottom trace, cADPR $(2 \mu \mathrm{M})$ standard before boiling for $30 \mathrm{~min}$. cADPR elutes as a sharp peak at $6.2 \mathrm{~min}$.

determined to be $\sim 10$ times the ADP-ribosyl cyclase activity (Franco et al., 1993; Inageda et al., 1995). Similar results were obtained with a purified NADase from splenic lymphocytes (Kim et al., 1993). Therefore, the results obtained in this study are qualitatively consistent with what has been seen before. However, cADPR hydrolase activity in the astrocyte and AR cultures appears to be $\sim 100-200$ times the ADP-ribosyl cyclase activity, based on loss of cADPR from the extracellular medium (Table 3 ). This could be attributable to the involvement of an NADase other than CD38, to modulation of CD38 resulting in different relative synthetic and hydrolytic rates, or to the hydrolytic action of an enzyme other than cADPR hydrolase on cADPR. For example, we have acquired evidence for the existence of a novel extracellular cyclic nucleotide phosphodiesterase in cortical cultures (Rosenberg and Dichter, 1989; Rosenberg and Li, 1994), and it is possible that this as-yet uncharacterized enzyme might possess some activity against cADPR. Perhaps a more reliable estimate of cADPR hydrolytic activity may be obtained by basing it on the accumulation of ADPR (Table 3). In this case, cADPR hydrolase activity would be 29 and 19 times the synthetic activity, values quantitatively similar to those found previously for a splenic NADase (Kim et al., 1993).

The results presented here suggest that most of the ADPribosyl cyclase activity in cells derived from embryonic rat cerebral 
Table 2. Evidence for cADPR hydrolase activity in cultures derived from rat cerebral cortex

\begin{tabular}{lcc} 
& cADPR & ADPR \\
\hline Control & $234 \pm 14$ & $9.9 \pm 1.9$ \\
& $n=12$ & $n=12$ \\
Astrocytes & $216 \pm 22$ & $12.6 \pm 2$ \\
& $n=8$ & $n=8$ \\
AR cultures & $p<0.05$ & $p<0.01$ \\
& $212 \pm 10$ & $13.5 \pm 1.1$ \\
& $n=8$ & $n=8$ \\
& $p<0.05$ & $p<0.001$
\end{tabular}

Cultures were incubated with $300 \mu \mathrm{M}$ cADPR for $60 \mathrm{~min}$ at $37^{\circ} \mathrm{C}$, after which samples of the medium were taken for direct assay of cADPR and ADPR by HPLC. For comparison, to control for the possibility of nonenzymatic hydrolysis, medium containing $300 \mu \mathrm{M}$ cADPR was incubated under similar conditions without cells. At the end of the incubation period, medium was collected and assayed by HPLC. Analysis of significance was by Student's two-tailed unpaired $t$ test. The mean protein of astrocyte cultures in these experiments was $54 \pm 7 \mu \mathrm{g}$, and for mixed cultures it was $99 \pm 19 \mu \mathrm{g}$ per $12 \mathrm{~mm}$ coverslip culture. Concentrations are given in micromolars. Data are pooled from four separate experiments, and number of determinations $(n)$ are given that were performed.

Table 3. ADP-ribosyl cyclase and cADPR hydrolase activity in cultures derived from rat cerebral cortex

\begin{tabular}{lllc} 
& Astrocytes & $\begin{array}{l}\text { AR } \\
\text { cultures }\end{array}$ & $\begin{array}{l}\text { AP } \\
\text { cultures }\end{array}$ \\
\hline $\begin{array}{l}\text { ADP-ribosyl cyclase [nmol } \\
\text { cADPR synthesized/mg }\end{array}$ & $0.84 \pm 0.06$ & $0.96 \pm 0.18$ & ND \\
protein/hr (mean \pm SEM)] & & & \\
cADPR hydrolase (1) (nmol & 167 & 111 & ND \\
cADPR degraded/mg & & & \\
protein/hr) & & & \\
cADPR hydrolase (2) (nmol & 24 & 18 & ND \\
$\begin{array}{l}\text { ADPR accumulation/mg } \\
\text { protein/hr) }\end{array}$ & & & \\
\hline
\end{tabular}

For determination of ADP-ribosyl cyclase activity, cultures were incubated with $1 \mathrm{~mm}$ NAD in HBSS for $1 \mathrm{hr}$ at $37^{\circ} \mathrm{C}$ in a shaking water bath, after which medium samples were bioassayed for CADPR activity (see text). cADPR hydrolase rates are given based both on cADPR loss and on ADPR gain in extracellular medium, based on data shown in Table 2. ND, Not detectable.

cortex is extracellular and that this extracellular activity is associated with astrocytes but not neurons. However, all that is known about the biological role of cADPR as a mobilizer of calcium release presumes an intracellular site of action. The cADPR produced by extracellular cyclase could therefore have a novel biological function, could somehow be transported inside the cell to exert its known effect there, or could be involved in activation of NADases, which themselves might play a key role in signal transduction (Kim et al., 1994).

\section{REFERENCES}

Bradford MM (1976) A rapid and sensitive method for the quantitation of microgram quantities of protein utilizing the principle of protein-dye binding. Anal Biochem 72:248-254.

Bredt DS, Snyder SH (1989) Nitric oxide mediates glutamate-linked enhancement of cGMP levels in the cerebellum. Proc Natl Acad Sci USA 86:9030-9033.

Clapper DL, Walseth TF, Dargie PA, Lee HC (1987) Pyridine nucleotide metabolites stimulate calcium release from sea urchin egg microsomes desensitized to inositol triphosphate. J Biol Chem 262:9561-9568.

Currie KPM, Swann K, Galione A, Scott RH (1992) Activation of $\mathrm{Ca}^{2+}$ dependent currents in cultured rat dorsal root ganglion neurones by a sperm factor and cyclic ADP-ribose. Mol Biol Cell 3:1415-1425.
Dargie PA, Agre MC, Lee HC (1990) Comparison of $\mathrm{Ca}^{2+}$ mobilizing activities of cyclic ADP-ribose and inositol triphosphate. Cell Regul 1:279-290.

Ehrlich BE, Kaftan E, Bezprozvannaya S, Bezprozvanny I (1994) The pharmacological of intracellular $\mathrm{Ca}^{2+}$-release channels. Trends Pharmacol Sci 15:145-149.

Franco L, Zocchi E, Guida L, Benatti U, Bargellesi A, Malavasi F, Lee HC, De Flora A (1993) A single protein immunologically identified as CD38 displays NAD+ glycohydrolase, ADP-ribosyl cyclase and cyclic ADP-ribose hydrolase activities at the outer surface of human erythrocytes. Biochem Biophys Res Commun 196:1459-1465.

Galione A, Lee HC, Busa WB (1991) $\mathrm{Ca}^{2+}$-induced $\mathrm{Ca}^{2+}$ release in sea urchin egg homogenates: modulation by cyclic ADP-ribose. Science 253:1143-1146.

Galione A, White A, Willmott N, Turner M, Potter BVL, Watson SP (1993) cGMP mobilizes intracellular $\mathrm{Ca}^{2+}$ in sea urchin eggs by stimulating cyclic ADP-ribose synthesis. Nature 365:456-459.

Graeff RM, Walseth TF, Hill HK, Lee HC (1996) Fluorescent analogs of cyclic ADP-ribose: synthesis, spectral characterization, and use. Biochemistry 35:379-386.

Graeff RS, Walseth TF, Fryxell K, Branton WD, Lee HC (1994) Enzymatic synthesis and characterizations of cyclic GDP-ribose. J Biol Chem 269:30260-30267.

Gu Q-M, Sih CJ (1994) Cyclic ADP-ribose: synthesis and structural assignment. J Am Chem Soc 116:7481-7486.

Harris KM, Rosenberg PA (1993) Localization of synapses in rat cortical cultures. Neuroscience 53:495-508.

Howard M, Grimaldi JC, Bazan JF, Lund FE, Santos-Argumedo L, Parkhouse RME, Walseth TF, Lee HC (1993) Formation and hydrolysis of cyclic ADP-ribose catalyzed by lymphocyte antigen CD38. Science 262:1056-1059.

Hua S-Y, Tokimasa T, Takasawa S, Furuya Y, Nohmi M, Okamoto H, Kuba K (1994) Cyclic ADP-ribose modulates $\mathrm{Ca}^{2+}$ release channels for activation by physiological $\mathrm{Ca}^{2+}$ entry in bullfrog sympathetic neurons. Neuron 12:1073-1079.

Inageda K, Takahashi K, Tokita K, Nishina H, Kanaho Y, Kukimoto I, Kontani K, Hoshino S, Katada T (1995) Enzyme properties of Aplysia ADP-ribosyl cyclase: comparison with NAD glychohydrolase of CD38 antigen. J Biochem 117:125-131.

Kim H, Jacobson EL, Jacobson MK (1993) Synthesis and degradation of cyclic ADP-ribose by NAD glycohydrolases. Science 261:1330-1333.

Kim H, Jacobson EL, Jacobson MK (1994) NAD glycohydrolases: a possible function in calcium homeostasis. Mol Cell Biochem 138:237-243.

Klingman JG, Hartley DM, Choi DW (1990) Automated determination of excitatory amino acid neurotoxicity in cortical culture. J Neurosci Methods 31:47-51.

Koguma T, Takasawa S, Karasawa T, Furuya Y, Yonekura H, Okamoto H (1994) Cloning and characterization of cDNA encoding rat ADPribosyl cyclase/cyclic ADP-ribose hydrolase (homologue to human CD38) from islets of Langerhans. Biochim Biophys Acta 1223:160-162.

Koh J-y Choi DW (1987) Quantitative determination of glutamate mediated cortical neuronal injury in cell culture by lactate dehydrogenase efflux assay. J Neurosci Methods 20:83-90.

Koshiyama H, Lee HC, Tashjian AHJ (1991) Novel mechanism of intracellular calcium release in pituitary cells. J Biol Chem 266:16985-16988.

Lee HC (1993) Potentiation of calcium-and-caffeine-induced calcium release by cyclic ADP-ribose. J Biol Chem 268:293-299.

Lee HC (1994) Cyclic ADP-ribose: P.A. calcium mobilizing metabolite of NAD+. Mol Cell Biochem 138:229-235.

Lee HC, Aarhus R (1991) ADP-ribosyl cyclase: an enzyme that cyclizes NAD+ into a calcium-mobilizing metabolite. Cell Regul 2:203-209.

Lee HC, Aarhus R (1993) Wide distribution of an enzyme that catalyzes the hydrolysis of cyclic ADP-ribose. Biochim Biophys Acta 39:68-74.

Lee HC, Zocchi E, Guida L, Franco L, Benatti U, De Flora A (1993) Production and hydrolysis of cyclic ADP-ribose at the outer surface of human erythrocytes. Biochem Biophys Res Commun 191:639-645.

Lee HC, Aarhus R, Graeff R, Gurnack ME, Walseth TF (1994) Cyclic ADP-ribose activation of the ryanodine receptor is mediated by calmodulin. Nature 370:307-309.

Levison SW, McCarthy KD (1991) Astroglia in culture. In: Culturing nerve cells (Banker G, Goslin K, eds), pp 309-336. Cambridge, MA: MIT.

Madison DV, Nicoll RA (1982) Noradrenaline blocks accommodation of pyramidal cell discharge in the hippocampus. Nature 299:636-638. 
Madison DV, Nicoll RA (1986a) Actions of noradrenaline recorded intracellularly in rat hippocampal CA1 pyramidal neurones, in vitro. J Physiol (Lond) 372:221-244.

Madison DV, Nicoll RA (1986b) Cyclic adenosine 3',5'-monophosphate mediates beta-receptor actions of noradrenaline in rat hippocampal pyramidal cells. J Physiol (Lond) 372:245-259.

Meszaros LG, Bak J, Chu A (1993) Cyclic ADP-ribose as an endogenous regulator of the non-skeletal type ryanodine receptor $\mathrm{Ca}^{2+}$ channel. Nature 364:76-79.

Mizuguchi M, Otsuka N, Sato M, Ishii Y, Kon S, Yamada M, Nishina H, Katada T, Ikeda K (1995) Neuronal localization of CD38 antigen in the human brain. Brain Res 697:235-240.

Rosenberg PA (1991) Accumulation of extracellular glutamate and neuronal death in astrocyte-poor cortical cultures exposed to glutamine. Glia 4:91-100.

Rosenberg PA, Dichter MA (1989) Extracellular cAMP accumulation and degradation in rat cerebral cortex in dissociated cell culture. J Neurosci 9:2654-2663.

Rosenberg PA, Li Y (1994) Beta-Adrenergic receptor-mediated regulation of extracellular adenosine in cerebral cortex in culture. J Neurosci 14:2953-2965.

Rusinko N, Lee HC (1989) Widespread occurrence in animal tissues of an enzyme catalyzing the conversion of NAD + into a cyclic metabolite with intracellular $\mathrm{Ca}^{2+}$-mobilizing activity. J Biol Chem 264:11725-11731.
Snell CR, Snell PH, Richards CD (1984) Degradation of NAD by synaptosomes and inhibition by nicotinamide mononucleotide: impact for the role of NAD as a synaptic modulator. J Neurochem 43:1610-1615.

States DJ, Walseth TF, Lee HC (1992) Similarities in amino acid sequences of Aplysia ADP-ribosyl cyclase and human lymphocyte antigen CD38. Trends Biochem Sci 17:495.

Summerhill RJ, Jackson DG, Galione A (1993) Human lymphocyte antigen CD38 catalyzes the production of cyclic ADP-ribose. FEBS Lett 335:231-233.

Takasawa S, Nata K, Yonekura H, Okamoto H (1993a) Cyclic ADPribose in insulin secretion from pancreatic b cells. Science 259:370-373.

Takasawa S, Tohgo A, Noguchi N, Koguma T, Nata K, Sugimoto T, Yonekura H, Okamoto H (1993b) Synthesis and hydrolysis of cyclic ADP-ribose by human leukocyte antigen CD38 and inhibition of the hydrolysis by ATP. J Biol Chem 268:26052-26054.

Trimmer PA, Evans T, Smith MM, Harden TK, McCarthy KD (1984) Combination of immunocytochemistry and radioligand receptor assay to identify beta-adrenergic receptor subtypes on astroglia in vitro. J Neurosci 4:1598-1606.

Walseth TF, Aarhus R, Zeleznikar RJJ, Lee HC (1991) Determination of endogenous levels of cyclic ADP-ribose in rat tissues. Biochim Biophys Acta 1094:113-120.

White AM, Watson SP, Galione A (1993) Cyclic ADP-ribose-induced $\mathrm{Ca}^{2+}$ release from rat brain microsomes. FEBS Lett 318:259-263. 